\title{
OUTCOME OF SLEEPINESS AND FATIGUE SCORES IN OBSTRUCTIVE SLEEP APNEA SYNDROME PATIENTS WITH AND WITHOUT RESTLESS LEGS SYNDROME AFTER NASAL CPAP
}

\author{
Raimundo Nonato Delgado Rodrigues" ${ }^{1}$ Aída Alexandra Alvim de Abreu e Silva \\ Rodrigues², Riccardo Pratesi3 ${ }^{3}$, Marília Miranda Fortes Gomes", \\ Ana Maria Nogales Vasconcelos ${ }^{5}$, Christine Erhardt ${ }^{6}$, Jean Krieger ${ }^{7}$
}

\begin{abstract}
Background and Purpose: The association of obstructive sleep apnea syndrome (OSAS) and restless legs syndrome (RLS) has been reported in the literature for many years. Both conditions may be responsible for fatigue and somnolence complaints secondary to nocturnal sleep disruption. The primary concern of this study is to evaluate the outcome of fatigue and daytime sleepiness symptoms at baseline and after continuous positive air pressure (CPAP) treatment in OSAS patients with and without RLS. Method: A prospective and comparative study between a group of 13 patients with OSAS and a group of 17 patients with OSAS+RLS. Laboratory blood tests and polysomnography were performed at baseline. The Epworth Sleepiness Scale (ESS) and the Pichot's questionnaire of fatigue/depression (PIC) were applied before and after 3 months of CPAP treatment. Results were compared. Results: No significant differences were found on PSG and laboratory results at baseline. Both groups had similar ESS and PIC scores at baseline $(p=0.73$ and 0.08 , respectively). After $n-C P A P, O S A S+R L S$ patients showed higher ESS and PIC scores ( $p=0.017$ and 0.03 , respectively). Conclusions: Despite a favorable general response, $n$-CPAP seemed less effective in treating fatigue and sleepiness in the OSAS+RLS group.
\end{abstract}

KEY WORDS: OSAS, RLS, fatigue, sleepiness, ESS, Pichot.

\begin{abstract}
Evolução dos índices de sonolência e fadiga em pacientes com síndrome da apnéia obstrutiva do sono portadores ou não de associação com síndrome das pernas inquietas após CPAP nasal

RESUMO - Objetivo: A associação síndrome de apnéia obstrutiva do sono / síndrome de pernas inquietas (SAOS-SPI) tem sido mencionada na literatura há muito. Ambas podem ser responsáveis por queixas de fadiga e sonolência secundárias à fragmentação do sono noturno. O objetivo deste estudo é avaliar a evolução dos sintomas de fadiga e sonolência diurna excessiva antes e após o tratamento com pressão aérea positiva contínua (CPAP) em pacientes portadores de SAOS, com e sem SPI. Método: Estudo prospectivo e comparativo entre um grupo de 13 pacientes com SAOS e um grupo de 17 com SAOS +SPI. Exames laboratoriais e polissonografia (PSG) foram realizados no início do estudo. A escala de sonolência de Epworth (ESE) e o questionário de fadiga/depressão de Pichot (PIC) foram aplicados antes do tratamento com CPAP e 3 meses após. Os resultados foram comparados. Resultados: No início do estudo não foram encontradas diferenças significativas na avaliação laboratorial e PSG. Ambos os grupos apresentavam inicialmente pontuação semelhante na avaliação da ESE e PIC ( $p=0,73$ e 0,08, respectivamente). Após CPAP, os pacientes SAOS+SPI apresentaram maiores ESE e PIC ( $p=0,017$ e 0,03, respectivamente). Conclusão: Apesar de resposta inicial favorável em ambos os grupos, o CPAP foi aparentemente menos eficaz na redução das queixas de fadiga e sonolência nos pacientes apnéicos com associação a SPI.
\end{abstract}

PALAVRAS-CHAVE: SAOS, síndrome das pernas inquietas, fadiga, sonolência, escala de sonolência de Epworth, Pichot.

\footnotetext{
${ }^{1}$ Neurologist, PhD, Hospital Universitário de Brasília, Brasília DF, Brazil; ${ }^{2}$ Pulmonologist, MD, Hospital Universitário de Brasília, Brasília DF, Brazil; ${ }^{3}$ Neurologist, PhD, Universidade de Brasília, Brasília DF, Brazil (UnB); ${ }^{4}$ Statistician, MS, Department of Statistics, UnB; ${ }^{5}$ Statistician, PhD, Department of Statistics, UnB; ${ }^{6}$ Neurologist, MD, Chef de Clinique, Hospices Civils de Strasbourg; ${ }^{7}$ Neurologist, PhD, Chef de Service, Service d'Exploration Fonctionelle du Système Nerveux et de Pathologie du Sommeil, Université Louis Pasteur (ULP) Hospices Civils de Strasbourg, France. The first author of this study was sponsored by a scholarship from CAPES (Coordenação de Aperfeiçoamento de Pessoal de Nível Superior), Programa 5300101005P-7, Ministry of the Education, Brazilian Government.
}

Received 21 June 2006, received in final form 21 September 2006. Accepted 8 November 2006. 
The association of obstructive sleep apnea syndrome (OSAS) and restless legs syndrome (RLS) has been described for many years ${ }^{1,2}$. As both conditions are frequent in the general population some difficulties in differential diagnosis may arise since both greatly disrupt nocturnal sleep, causing fatigue, limb motor hyperactivity and daytime sleepiness ${ }^{3}$. In addition, some sleep laboratories may not have surface electromyographic analysis of the anterior tibialis muscle as a routine procedure during polysomnographies and therefore many nocturnal limb movements (seen in about $85 \%$ of RLS patients ${ }^{4}$ ) may easily pass unnoticed or be attributed only to respiratory effort ${ }^{5}$. In fact, the details of that interesting association have not been fully elucidated. For instance, the need to treat both conditions simultaneously and their individual influence on daytime sleepiness and fatigue complaints are not fully understood.

A common relationship has been suggested, however, related to a possible dysfunction of brainstem centers ${ }^{2}$. Nonetheless, to our knowledge, there is no description or clear evidence of a central nervous system disturbance resultant from OSAS and RLS in a same patient. Furthermore, the frequent concomitant occurrence of metabolic syndrome in OSAS patients $s^{6,7}$ constitutes another important causative factor (i.e. relative iron overload) for limb motor abnormalities ${ }^{8}$.

On the other side it is interesting to notice that continuous positive air pressure (CPAP) treatment may contribute to the reduction of fatigue and sleepiness complaints in RLS patients with associated OSAS.

Therefore, this study aimed at evaluating possible differences in sleepiness and fatigue response patterns, before and after CPAP treatment, between OSAS and OSAS+RLS-associated patients. In addition, we described this association in terms of its clinical, laboratory and polysomnographic features.

\section{METHOD}

Subjects - Seventeen OSAS patients, who met the diagnostic criteria for RLS (12 men and 5 women, mean age: $52 \pm$ 10 years, range: $29-69$ ), were consecutively identified ${ }^{9-11}$. In addition, 13 patients presenting only OSAS (10 men and 3 women, mean age: $54 \pm 4.8$ years, range: $45-62$ ) were also selected. Patients had been admitted to the Strasbourg University Sleep Disorders Unit for the initial OSAS workup and entered the study group after informed consent was obtained and the whole protocol received the approval of our Institution's Ethics Committee. All 30 patients presented periodic leg movements (PLM) as well, except one (belonging to the OSAS group).

OSAS diagnosis was determined according to the following criteria: snoring, excessive daytime sleepiness and an apnea-hypopnea index greater than five events per hour of sleep. PLM diagnosis was made using the parameters described by Coleman ${ }^{12}$, while RLS was clinically determined employing international criteria ${ }^{13}$. All patients had been diagnosed with OSAS, RLS or PLM for the first time and had never received previous treatment for any of these disorders. Patients were divided into two groups: one comprised of OSAS patients $(n=13)$ and the second of OSAS+RLS-associated patients $(n=17)$.

General procedure - The protocol used in this study has been object of a previous publication where further details can be found ${ }^{9}$. Laboratory blood tests were performed in both groups, including blood glycemia, iron metabolism (serum transferrin and ferritin), TSHUs (thyroid stimulating hormone-ultra-sensitive) and T4 dosages. Body mass index (BMI) was also determined in all subjects.

A polysomnographic assessment (PSG) was conducted during a 4 night period spent at the Sleep Unit: (1) one night for habituation to the laboratory settings, (2) one for diagnostic purposes (polysomnographic night), (3) one for nasal-CPAP titration, and (4) one for employing nasal-CPAP with a fixed pressure, as determined during the previous night. The polygraphic digital systems used comprised of two Brainnet ${ }^{\circledR}$ Medatec and an Alice ${ }^{\circledR} 4$ Respironics both provided with a pneumotachograph (Tyco-Healthcare-Puritan Bennett ${ }^{\circledR}$ ) or a nasal canula coupled to a pressure transducer (Protech ${ }^{\circledR}$ Salter Labs) and an esophageal pressure sensor or a thoracic-abdominal strain gauge. Limb EMG was detected via surface electrodes placed over the right and left tibialis muscle. Biological calibration was held prior to recording and data were digitally stored and analyzed off-line. PLM were scored according to Coleman's criteria ${ }^{12}$

Sleep was visually scored according to Rechtschaffen and Kales criteria ${ }^{14}$. Microarousal criteria were those described by ASDA (later AASM) ${ }^{15}$.

Additional sleep parameters were included, defined as follows:

- Total sleep time (TST): time between the beginning and end of sleep (TSP) minus the time spent awake during the night;

- Sleep efficiency (SE): TST during the entire the recordings expressed as percentages;

- Percentage of stages 1 and 2 (PS 1-2): time spent in stages 1 and 2 during the TST;

- Percentage of stages 3 and 4 (PS 3-4): time spent in stages 3 and 4 during the TST;

- Percentage of REM (PREM): time spent in rapid-eye movement sleep during the TST;

- Index of arousals (IAr): total number of microarousals per hour of sleep;

- Apnea-hypopnea index (AHI): number of respiratory events occurring per hour of sleep;

- PLM index (PLMi): number of periodic leg movements occurring per hour of sleep.

Subjective daytime sleepiness and fatigue evaluation The Epworth Sleepiness Scale (ESS) scores ${ }^{16}$ were used to 
evaluate the patients' level of daytime sleepiness, while fatigue was measured employing the Pichot questionnaire $(\mathrm{PIC})^{17}$. The later is a practical 24 -item self-rating account with three homogeneous sub-scales of 8 items each which measure depressive mood, asthenia-fatigue and anxiety parameters, respectively. The asthenia-fatigue scale was used, consisting of 8 questions scored progressively from "0" (not at all) to "4" (extremely) (Table 1). Three months after initiating n-CPAP treatment, all patients returned to the Sleep Unit on an outpatient basis and had their daytime sleepiness and fatigue re-evaluated by applying the questionnaires described above.

Statistical analysis - Statistical analyses were performed using SPSS for Windows, v.13.0. Mann-Whitney tests were used to compare biometric, laboratory and polysomnographic data. Data before and after n-CPAP treatment were compared via Wilcoxon tests. Statistical significance was set at $p<0.05$.

\section{RESULTS}

Patient characteristics - Both groups presented a wide range of OSAS severity. Mean apnea-hypopnea index was 56 $\pm 35 / \mathrm{h}$ for group 1 and $44 \pm 27 / \mathrm{h}$ for group $2(p=0.14)$, and BMI was $34.7 \pm 9 \mathrm{Kg} / \mathrm{m}^{2}$ for group 1 and $34 \pm 8 \mathrm{Kg} / \mathrm{m}^{2}$ for group $2(\mathrm{p}=0.81)$. All subjects had low sleep efficiencies (mean: group 1 - 69+16\%, group $2-72 \pm 12 \% ; p=0.54)$ and a high microarousal index (mean: group 1 - 67 $\pm 28 / h$, group 2 - 44 $\pm 20 / h$; $p=0.11)$. Age $(p=0.5)$ and gender $(23.1 \%$ and $29.4 \%$ women in group 1 and 2, respectively) did not differ significantly between the two groups.

Clinical and laboratory characteristics - The baseline biochemical profile (Table 2) of both groups was not significantly different. Polysomnographic and nCPAP data are presented in Table 3.

Sleepiness, PLM index and fatigue - Similar baseline ESS scores were observed between the two groups $(p=0.73)$.

Following 3 months of n-CPAP treatment, ESS
Table 1. Pichot's questionnaire: items measuring the astheniafatigue dimension.

1) I feel short of stamina

2) Everything I do requires a huge effort

3) I have a feeling of weakness in certain parts of my body

4) My arms or legs are heavy

5) I feel tired for no reason

6) I feel like lying down and resting

7) I have difficulty to concentrate

8) I feel discouraged, my arms and legs are sore and heavy

scores decreased significantly. In OSAS patients, the mean score of $10.5 \pm 4.6$ observed prior to $n$-CPAP treatment was reduced to $4.7 \pm 4.9$ after treatment $(p=0.004)$. Similarly, the mean score of $10.6 \pm 4.8$ in OSAS+RLS patients decreased to $7.4 \pm 3.5$ ( $p=0.014)$. In addition, final ESS scores after $n$-CPAP differed significantly between groups $(p=0.017)$. This finding may suggest that n-CPAP treatment was less efficient at improving daytime sleepiness in OSAS+RLS patients.

Furthermore, periodic movements of OSAS sub-

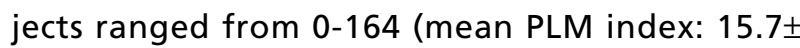
$27.2 / \mathrm{h}$ ), while in the OSAS+RLS group the PLM range was that of 3-127 (mean PLM index: 5.1 $\pm 3.4 / h ; p=$ $0.51)$.

Via Pichot's questionnaire we observed that fatigue scores were similar in both groups before treatment (Table 4). Scores decreased significantly, however, after n-CPAP treatment within both groups, particularly in the OSAS+RLS group (Table 4). Nonetheless, OSAS+RLS patients' final scores were still higher than those of the remaining subjects (OSAS group).

\section{DISCUSSION}

OSAS+RLS associations are observed in only 2.0$8.3 \%$ of OSAS patients ${ }^{18-20}$. Such small prevalence may be due, however, to the fact that RLS is in itself a

Table 2. Baseline biochemical profile of OSAS and OSAS+RLS patients.

\begin{tabular}{lcccc}
\hline Biochemical parameter & Normal values & Group 1 (OSAS) & Group 2 (OSAS+RLS) & $\mathrm{p}$ \\
\hline TSH (mUl/l) & $0.15-4.5$ & $1.7 \pm 0.8$ & $1.5 \pm 0.5$ & 0.23 \\
T4 (ng/l) & $11.6-26$ & $16.3 \pm 2.5$ & $15.4 \pm 2.69$ & 0.23 \\
Glucose (mmol/l) & $4.1-5.9$ & $6.5 \pm 3.1$ & $6.2 \pm 1.1$ & 0.36 \\
Transferrin (g/l) & $1.68-2.7$ (women) & $2.5 \pm 0.4$ & $2.3 \pm 0.67$ & 0.11 \\
& $1.70-2.8$ (men) & & & 0.17 \\
Ferritin (ug/l) & $14-186$ (women) & $156.9 \pm 130.4$ & $274.5 \pm 245.8$ & \\
& $32-284$ (men) & & &
\end{tabular}

$\mathrm{TSH}$, thyroid stimulating hormone; $\mathrm{T} 4$, thyroxin hormone. 
Table 3. Polysomnographic and n-CPAP data of OSAS and OSAS+RLS patients.

\begin{tabular}{lccc}
\hline & Group 1 (OSAS) & Group 2 (OSAS+RLS) & $p$ \\
\hline TST (hours) & $4.2 \pm 1.5$ & $4.8 \pm 0.7$ & 0.29 \\
SE (\%) & $69 \pm 0.16$ & $72 \pm 0.12$ & 0.54 \\
PSI-2 (\%) & $71.34 \pm 16.92$ & $70.34 \pm 22.38$ & 0.57 \\
PS3-4 (\%) & $13.74 \pm 11.75$ & $14.65 \pm 9.78$ & 0.81 \\
PREM (\%) & $14.91 \pm 8.43$ & $9.12 \pm 6.96$ & 0.11 \\
IAr (number/h) & $67.38 \pm 28.1$ & $44.54 \pm 19.97$ & 0.11 \\
IAH (number /h) & $56.11 \pm 35.25$ & $44.26 \pm 27.5$ & 0.41 \\
n-CPAP (cmH 20$)$ & $9.69 \pm 2.92$ & $9 \pm 2.93$ & 0.5 \\
\hline
\end{tabular}

TST, total sleep time; SE, sleep efficiency; PS1-2, percentage of stages 1 and 2; PS3-4, percentage of stages 3 e 4; PREM, percentage of REM; IAr, index of arousals; IAH, apnea-hypopnea index n-CPAP, positive pressure level.

Table 4. Fatigue scores observed before and after $n$-CPAP treatment.

\begin{tabular}{lccc}
\hline Fatigue score & $\begin{array}{c}\text { Group 1 } \\
\text { (OSAS) }\end{array}$ & $\begin{array}{c}\text { Group 2 } \\
\text { (OSAS+RLS) }\end{array}$ & $\begin{array}{c}\mathrm{p} \text { (between } \\
\text { groups) }\end{array}$ \\
\hline PIC (before CPAP) & $11.7 \pm 6.6$ & $16.6 \pm 7.3$ & 0.08 \\
PIC (after CPAP) & $5.1 \pm 6.1$ & $10.1 \pm 6.4$ & 0.03 \\
p (within-group) & 0.008 & 0.001 & \\
\hline
\end{tabular}

PIC, Pichot's questionnaire.

highly under-diagnosed condition ${ }^{21}$. In this context, the present study aimed at determining if the occurrence of RLS was associated to a clinically distinct OSAS profile or to a specific response of daytime sleepiness and fatigue complaints to n-CPAP therapy in two groups of patients with and without the association OSAS+RLS.

Our results indicated that OSAS and OSAS+RLS patients had similar baseline biochemical and biometric profiles. In fact, the concomitant occurrence of obesity, hyperglycemia or insulin resistance and high ferritin levels in OSAS patients may suggest an association to a metabolic syndrome or syndrome " $X " 6$. Some authors have even suggested that the definition of metabolic syndrome should be broadened to include OSAS ${ }^{22}$. In addition, serum ferritin levels are considered to be one of the main determinants of blood glucose and a good marker of insulin resistance ${ }^{23}$.

Importantly, polysomnographic data indicated that sleep quality tended to be low for all patients. In addition, sleepiness evaluation, respiratory disturbance index, PLM index and therapeutic positive pressure levels determined during the titration night were also similar in both groups. Thus, no major baseline clinical or polysomnographic differences were ob- served in the OSAS patients, regardless of a possible association with RLS.

Similarly, subjective baseline daytime sleepiness, evaluated by the ESS, did not differ among both groups. Furthermore, significant improvements in the ESS scores were observed in both groups following $\mathrm{n}$-CPAP treatment for 3 months, consonant with previous findings ${ }^{24}$. Such improvement is thought to occur in response to a reduction in sleep fragmentation, which stabilizes sleep structure, re-establishes correct oxyhemoglobin blood levels and decreases respiratory effort leading to a more refreshing night sleep $^{25}$. However, OSAS+RLS patients presented higher ESS scores, relative to OSAS subjects, regardless of the general improvement in sleepiness. Such result may suggest that these patients respond less favorably to n-CPAP therapy. To our knowledge, this is the first study to report that.

Similar baseline fatigue symptoms were found in both groups, although OSAS+RLS subjects presented higher absolute scores on the Pichot's question-

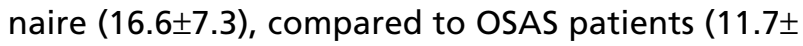
6.6). In general, all patients responded well to $\mathrm{n}$-CPAP therapy, with an important decrease in fatigue scores. When evaluated after the third month of treatment, OSAS+RLS patients still demonstrated higher fatigue scores.

Fatigue, like somnolence, is frequently viewed as a consequence of non-restorative sleep ${ }^{26}$, responding favorably to n-CPAP treatment in OSA ${ }^{27,28}$. The exact etiological generator of fatigue is still not clear, although many possible sources have been suggested, notably the brainstem, hypothalamus, autonomic nervous system and the neuroendocrine system ${ }^{29}$. Abnormal P300 latencies are considered a good tool for assessing fatigue symptoms ${ }^{29}$. 
In addition, our findings seem to suggest that correction of respiratory disturbance alone may not be sufficient to entirely overcome complaints of fatigue and daytime sleepiness in OSAS+RLS patients. Pathological changes in central pathways (at subcortical levels?), seen in RLS, could eventually have increased sleep disruption, adding to fatigue and somnolence and decreasing responsiveness to n-CPAP. It would be interesting in the future and within a larger group of patients, to study the influence of relative REM sleep deprivation in this context. At this point it would also be interesting to speculate on the need to treat OSAS+RLS patients for respiratory and motor symptoms separately, if the latter are to be considered a cause for the persistence of fatigue symptoms.

Additional studies are necessary to fully elucidate these aspects, including a larger number of patients, a longer follow-up period, and taking into account other factors such as n-CPAP compliance. In our study the compliance was evaluated (and reinforced) through personal or phone contact, which may not give a sufficient degree of certitude. A second polysomnographic evaluation would also be necessary following the onset of $n$-CPAP treatment in order to re-evaluate the macrostructure of sleep and compare sleepiness more objectively.

In summary, the present study demonstrated that the concomitant occurrence of RLS and OSAS does not seem to be associated to a significantly distinct basal clinical or laboratory OSAS profile. Following $n$-CPAP treatment, a positive response in terms of a decrease in fatigue and sleepiness scores was observed in both groups. Nevertheless, OSAS and OSAS+ RLS patients responded differently to the $n$-CPAP therapy, with higher residual fatigue and sleepiness scores persisting in the OSAS+RLS group. Such finding may be due to possible central dysfunctions observed in RLS. Thus, there seems to be a need to treat OSAS+RLS patients for both respiratory and motor symptoms.

Acknowledgements - We would like to express our appreciation to all members of the Sleep Unit at the Strasbourg University Hospital. Special thanks to Mrs. Chantal Petrazoller and Mrs. Anny Wolff, for their cooperation in the organization of this clinical study.

\section{REFERENCES}

1. Chokroverty S, Sachdeo R. Restless limb-myoclonus-sleep apnea syndrome. Ann Neurol 1984;16:124.

2. Schönbrunn E, Rieman D, Hohagen F, Berger M. Restless legs and sleep apnea syndrome: random coincidence or causal relation? Nervenarzt 1990;61:306-311.

3. Dorow $\mathrm{P}$, Thalhofer S. Restless legs syndrome and periodic leg movements during sleep in patients with sleep apnea: a therapeutic problem? Pneumologie 1997;51(Suppl 3):716-720.
4. Allen RP, Earley CJ. Restless legs syndrome: a review of clinical and pathophysiologic features. J Clin Neurophysiol 2001;18:128-147.

5. Lakshminarayanan S, Paramasivan KD, Walters AS, Wagner ML, Patel $\mathrm{S}$, Passi V. Clinically significant but unsuspected restless legs syndrome in patients with sleep apnea. Mov Disord 2005;20:501-503.

6. Wolk R, Shamsuzzaman ABS, Somers VK. Obesity, sleep apnea and hypertension. Hypertension 2003;42:1067-1074.

7. Svatikova A, Wolk R, Gami AS, Pohanka M, Somers VK. Interactions between obstructive sleep apnea and the metabolic syndrome. Curr Diab Rep 2005;5:53-58.

8. Krieger J, Schroeder C. Iron, brain and restless legs syndrome. Sleep Med Rev 2001;5:277-286.

9. Delgado Rodrigues RN, Abreu e Silva Rodrigues A, Pratesi R, Krieger J. Outcome of restless legs severity after continuous positive air pressure (CPAP) treatment in patients affected by the association of RLS and obstructive sleep apneas. Sleep Med 2006;7:235-239.

10. Montplaisir J, Boucher S, Poirier G, Lavigne G, Lapierre O, Lesperance P. Clinical, polysomnographic, and genetic characteristics of restless legs syndrome: a study of 133 patients diagnosed with new standard criteria. Mov Disord 1997;12:61-65.

11. The International Restless Legs Syndrome Study Group. Validation of the International Restless Legs Syndrome Study Group rating scale for restless legs syndrome. Sleep Medicine 2003;4:121-132.

12. Coleman RM, Bliwise DL, Sajben N, et al. Daytime sleepiness in patients with periodic movements in sleep. Sleep 1982;5(Suppl 2):S191-S202.

13. Allen RP, Picchietti D, Hening WA, Trenkwalder C, Walters AS, Montplaisir J. Restless legs syndrome: diagnostic criteria, special considerations, and epidemiology: a report from the restless legs syndrome diagnosis and epidemiology workshop at the National Institutes of Health. Sleep Medicine 2003;4:101-119.

14. Rechtschaffen A, Kales A. A manual of standardized terminology, techniques and scoring system for sleep stages of human subjects. Los Angeles: Brain Information Service. Brain Research Institute, University of California, Los Angeles, 1968.

15. EEG Arousals - Scoring Rules and Examples. A Preliminary Report from the Sleep Disorders Atlas Task Force of the American Sleep Disorders Association. Sleep 1992;15:174-184.

16. Johns MW. A new method for measuring daytime sleepiness: the Epworth sleepiness scale. Sleep 1991;14:540-545.

17. Pichot P, Brun JP. Questionnaire bref d'auto-évaluation des dimensions dépressive, asthénique et anxieuse. Ann Més-Psychol 1984;142:862-865.

18. Ohayon MM, Roth T. Prevalence of restless legs syndrome and periodic movement disorder in the general population. J Psychos Res 2002; 53:547-554.

19. Sharokh J, Abraham WT, Brown C, Nishiyama H, Giesting R, Wagoner LE. Prevalence of obstructive sleep apnoea and periodic limb movement in 45 subjects with heart transplantation. Eur Heart J 2004;25: 260-266.

20. Lakshminarayanan S, Paramasivan KD, Walters AS, Wagner ML, Patel $\mathrm{S}$, Passi V. Clinically significant but unsuspected restless legs syndrome in patients with sleep apnea. Mov Disord 2005;20:501-503.

21. Zucconi M, Ferini-Strambi L. Epidemiology and clinical findings of restless legs syndrome: Udine Special Section. Sleep Medicine 2004; 5:293-299.

22. Wilcox I, McNamara SG, Collins FL, Grunstein RR, Sullivan CE. "Syndrome Z": the interaction of sleep apnoea, vascular risk factors and heart disease. Thorax 1998;53:25-28.

23. Fernandez-Real JM, Ricart-Engel W, Arroyo E, et al. Serum ferritin as a component of insulin resistance syndrome. Diabetes Care 1998;21: 62-68.

24. Zimmermann C, Kohler D, Schonhofer B. Value of retrospective assessment of the Epworth sleepiness scale after long-term CPAP therapy in obstructive sleep apnea disorder. Pneumologie 2000;54:572-574.

25. Zamagni M, Sforza E, Boudewijns A, Petiau C, Krieger J. Respiratory effort: a factor contributing to sleep propensity in patients with obstructive sleep apnea. Chest 1996;109:651-658.

26. Paty J, Morault P, Berthomieu J. Fatigue, drowsiness and sleep. Bull Acad Natl Med 1994;178:1087-1105.

27. Marquez-Baez C, Paniagua-Soto J, Castilla-Garrido JM. Tratamiento con CPAP del sindrome de apneas del sueño: cumplimiento, efectividad y efectos secundarios. Rev Neurol 1998;26:375-380.

28. McMahon JP, Foresman BH, Chisholm RC. The influence of CPAP on neurobehavioral performance of patients with obstructive sleep apnea hypopnea syndrome: a systematic review. WMJ 2003;102:36-43.

29. Kaseda Y, Jiang CH, Kurokawa K, Mimori Y, Nakamura S. Objective evaluation of fatigue by event-related potentials. J Neurol Sci 1998;158: 96-100. 